\title{
Projeto PIBID e Atendimento Educacional Especializado: uma experiência com o uso de jogos e materiais concretos na construção de conceitos de Matemática pelos estudantes
}

\section{PIBID Project and Special Educational Service: an experience with the use of games and manipulatives materials in the construction of Mathematics concepts by students}

\author{
Thaylles Leal da Rosa \\ Universidade Federal do Rio Grande do Sul (UFRGS), Porto Alegre, RS, Brasil \\ https://orcid.org/0000-0002-9229-7635, thayllesleal@gmail.com
}

\begin{abstract}
Mayara Costa da Silva
Universidade Federal do Rio Grande do Sul (UFRGS), Colégio de Aplicação, Pós-Graduação em Educação (PPGEDU/UFRGS), Porto Alegre, RS, Brasil https://orcid.org/0000-0001-8716-0768, mayacsilva@gmail.com
\end{abstract}

\begin{abstract}
Rodrigo Sychocki da Silva
Universidade Federal do Rio Grande do Sul (UFRGS), Programa de Pós-Graduação em Ensino de Matemática (PPGEMAT), Porto Alegre, RS, Brasil https://orcid.org/0000-0002-7406-2517, sychocki.rodrigo@gmail.com
\end{abstract}

\section{Informações do Artigo}

Como citar este artigo

ROSA, Thaylles Leal da; SILVA, Mayara

Costa da; SILVA, Rodrigo Sychocki da.

Projeto PIBID e Atendimento Educacional

Especializado: uma experiência com o uso de jogos e materiais concretos na construção de conceitos de Matemática pelos estudantes. REMAT: Revista Eletrônica da Matemática, Bento Gonçalves, RS, v. 6, n. 2, p. e2001, 28 jul. 2020. DOI:

https://doi.org/10.35819/remat2020v6i2id3965

Histórico do Artigo

Submissão: 20 de março de 2020

Aceite: 9 de maio de 2020

\section{Palavras-chave}

Educação Especial

Educação Matemática

Jogos

Materiais Concretos

\section{Resumo}

O presente texto emerge como um produto reflexivo a partir de um conjunto de experiências vivenciadas no âmbito do Projeto de Iniciação à Docência (PIBID), ocorrido no espaço de Atendimento Educacional Especializado (AEE). A partir de demandas emergentes das aulas regulares de Matemática, considerou-se a possibilidade de elaborar materiais/aulas que fossem subsidiados no uso de jogos e materiais concretos. Para tal intento foram consultadas na literatura ideias que pudessem fundamentar a construção e uso dos materiais descritos no presente artigo. A fundamentação teórica utilizada perpassa por elementos característicos na legislação nacional, que envolve a Educação Especial na perspectiva da Educação Inclusiva e, também, no uso de jogos e materiais concretos para a promoção de uma aprendizagem matemática reflexiva. A partir de uma metodologia de trabalho fundamentada em ações no AEE, observações sobre os participantes e anotações no diário de campo, foi possível refletir, sob uma perspectiva qualitativa, sobre o itinerário percorrido pelos estudantes participantes, relacionando-o com sua contemplação diante dos objetivos antecipadamente elaborados. A realização das ações do projeto também oportunizou realizar reflexões sobre a formação inicial do professor de Matemática, no que tange a sua apropriação das ideias e formas de trabalho pertinentes ao AEE.

\section{Abstract}

This text emerges as a reflective product from a set of experiences lived within the scope of the Teaching Initiation Project (PIBID), that took place in the Special Educational Service (AEE) space. From the demands emerging from regular mathematics classes, the possibility of developing materials/classes that were subsidized in the use of games and manipulatives was considered. For this purpose, ideas that could support the construction and use of the materials described in this article were consulted in the literature. The theoretical basis used runs through characteristic elements in 
national legislation, which involves Special Education from the perspective of Inclusive Education and also in the use of games and manipulatives to promote reflective mathematical learning. From a methodology based on actions in the AEE, observations on the participants and notes in the field diary, it was possible to reflect, from a qualitative perspective, on the itinerary taken by the participating students, relating it to their contemplation before the objectives in advance elaborated. The performance of the project's actions also made it possible to reflect on the initial training of the mathematics teacher, regarding its appropriation of the ideas and ways of working pertinent to the AEE.

\section{Introdução e motivação para o trabalho}

O presente artigo se propõe a apresentar e refletir sobre um conjunto de atividades envolvendo Matemática, as quais foram planejadas, desenvolvidas e aplicadas no âmbito do Atendimento Educacional Especializado (AEE). Os encontros ocorreram vinculados à área da Educação Especial, no Ensino Médio do Colégio de Aplicação, da Universidade Federal do Rio Grande do Sul, onde os estudantes também foram atendidos em conjunto com a professora responsável por esse atendimento. Além do contato regular com a professora de Educação Especial, também foram realizados encontros do bolsista participante do projeto com os professores de Matemática da escola. Esses professores apresentavam as demandas e retornavam com feedbacks sobre a repercussão das atividades e reflexões em relação à aprendizagem na sala de aula regular dos estudantes atendidos. O conjunto de atividades, bem como a organização metodológica de trabalho, ocorreu em 2019 por meio do Programa Institucional de Bolsas de Iniciação à Docência (PIBID) da Matemática, da Universidade Federal do Rio Grande do Sul.

As atividades envolveram jogos e materiais concretos, os quais possibilitaram a interação dos estudantes, público-alvo da Educação Especial, com os conceitos matemáticos abordados. $\mathrm{O}$ objetivo central do trabalho desenvolvido foi oportunizar aos estudantes a participação em momentos em que, a partir da observação, da análise de regularidades e do estabelecimento de relações entre os elementos envolvidos na atividade, pudessem ser construídos conceitos de Matemática. Tal objetivo estava alinhado com o pensamento de que a forma de trabalho realizada no projeto PIBID tivesse relação com as aprendizagens da sala de aula regular e estivessem em sintonia com os objetivos estabelecidos pelas normativas em relação à Educação Especial. Logo, as ações executadas almejavam que os estudantes tivessem experiências de ensino diversificadas com relação aos conteúdos abordados nas aulas regulares de Matemática, atuando no sentido de complementar o processo de aprendizagem dos estudantes, porém sem configurar a sala de AEE como uma espécie de reforço escolar, tal como salienta Santos (2017, p. 79):

Como um atendimento complementar e suplementar este serviço visa ao acesso e permanência com qualidade do aluno com deficiência no sistema regular de ensino, pois não tem o papel de substituição ao ensino comum, nem tem a finalidade de ser um reforço escolar. 
A partir das ações feitas na escola, por intermédio do projeto PIBID, observou-se que a literatura consultada ao longo dos planejamentos e a prática desenvolvida estavam de alguma maneira influenciando a forma de trabalho e o olhar diante da complexidade e diversidade educacional encontrada. Após a conclusão do conjunto de ações integrantes do projeto, visualizou-se a produção do presente artigo; nele, percebeu-se a possibilidade de veicular a reflexão e a divulgação da experiência vivenciada podendo, assim, oportunizar o desenvolvimento de novas propostas, semelhantes a essa, em outros contextos escolares.

O presente artigo está organizado da seguinte maneira: na seção 2 , há uma explanação sobre a Educação Especial na perspectiva da Educação Inclusiva, com base em autores que apresentam e refletem sobre o tema e em documentos normativos relativos à área; na seção 3 , apresentam-se os referenciais teóricos sobre jogos e materiais concretos usados no âmbito educacional; na seção 4, disserta-se sobre a metodologia, característica, materiais e método de trabalho ocorridos ao longo dos encontros; a seção 5 traz uma análise sobre o uso dos materiais relacionando com a perspectiva teórica do estudo; e, por fim, na seção 6 tecem-se considerações e reflexões finais sobre a experimentação.

\section{Referencial Teórico}

\subsection{Educação Especial na perspectiva da Educação Inclusiva}

De acordo com a literatura acadêmica que envolve a área da Educação Especial, especificamente os estudos sobre formação docente (BRABO, 2013; PIOVEZANI, 2013), tem sido recorrente a queixa de que a discussão sobre Educação Especial nos cursos de licenciaturas tem se mostrado insuficiente, motivo pelo qual o discurso do despreparo docente aparece de forma intensa quando relacionado à atuação junto aos estudantes público-alvo da Educação Especial. Neste sentido, a não obrigatoriedade de uma disciplina específica que envolva a área nos cursos de licenciatura, com exceção da Língua Brasileira de Sinais (LIBRAS), contribui para uma fragmentação entre os componentes curriculares. Assim, na busca por compreendermos a constituição da perspectiva inclusiva em Educação Especial e a atuação docente, tornou-se relevante refletir sobre os movimentos e os processos históricos que envolvem a área.

A primeira Lei de Diretrizes e Bases da Educação Nacional (LDB), promulgada em dezembro de 1961, Lei n 4.024/61 (BRASIL, 1961), determinou que a educação de todos os sujeitos deveria ser preferencialmente realizada no sistema geral de educação. Posteriormente a isso, pelo fato do sistema de educação regular não atender satisfatoriamente as demandas para uma Educação Especial de qualidade, em 1971, foi aprovada a lei de 5.962/1971 (BRASIL, 1971), a qual alterava a LDB de 1961, ao propor, em seu artigo $n^{\circ}$ 9, que

Os alunos que apresentem deficiências físicas ou mentais, os que se encontrem em atraso considerável quanto à idade regular de matrícula e os superdotados deverão receber tratamento especial, de acordo com as normas fixadas [...] (BRASIL, 1971, p. 3). 
Com essa mudança, o governo da época reconheceu e reforçou que a Educação Especial fosse ofertada por instituições especializadas.

Em 1977, foi lançado o primeiro Plano Nacional de Educação Especial que objetivava, entre outras questões, atender a demanda da formação de professores e técnicos para o trabalho junto aos sujeitos público-alvo da Educação Especial, sendo uma das primeiras políticas de formação docente para o trabalho de Educação Especial. No entanto, é a partir da década de 90 que ocorrem mudanças no âmbito político nacional, as quais se juntam aos movimentos e conferências internacionais promovendo uma amplitude de debate, em que as políticas educacionais voltadas para a Educação Especial começam a ser reorganizadas e reestruturadas de forma substancial.

A partir de uma perspectiva do ponto de vista pedagógico, Soares e Carvalho (2012, p. 32) refletem sobre a falta de profissionais capacitados que possam estar aptos ao atendimento:

Parte desta avaliação se voltava à política educacional, como a oferta de vagas inferior à demanda, inadequação da rede física e insuficiência de recursos materiais, carência de técnicos para orientação e acompanhamento da programação pedagógica e falta de política consistente visando à integração desses alunos no sistema regular de ensino.

Alinha-se a isso, a Lei de Diretrizes e Bases de 1996, que tem como princípio a Educação para todos; ao que se refere à Educação Especial, garante, em seu artigo quarto, um atendimento educacional "especializado gratuito aos educandos com deficiência, transtornos globais do desenvolvimento e altas habilidades ou superdotação, transversal a todos os níveis, etapas e modalidades, preferencialmente na rede regular de ensino" (BRASIL, 1996, art. $4^{\circ}$ ). Além disso, promover a manutenção de programas para a formação de pessoal especializado. Assim, nota-se a relevância de se oportunizar e realizar em cursos de formação inicial de professores, a partir de disciplinas ou projetos, ações e reflexões que envolvam a temática da Educação Especial.

Torna-se importante destacar que a Política Nacional de Educação Especial, na perspectiva da Educação Inclusiva (BRASIL, 2008), constituiu-se como um marco para o atendimento educacional especializado na medida em que indicou que o mesmo ocorresse de forma complementar ou suplementar, e não mais em caráter substitutivo. $O$ atendimento educacional especializado é um serviço da Educação Especial que identifica, elabora e organiza recursos pedagógicos e que transforma acessível e de qualidade a participação dos estudantes para o ensino, considerando suas especificidades. O documento em questão (BRASIL, 2008), além de representar a alteração da perspectiva política para a área, também alterou a nomenclatura utilizada para se referir aos sujeitos público-alvo da Educação Especial, passando a apresentar os conceitos de pessoas com deficiência, transtornos globais de desenvolvimento e altas habilidades/superdotação.

Assim, estabeleceu-se como prioridade que o AEE fosse um serviço a ser ofertado no contraturno das aulas regulares dos estudantes, proporcionando ao estudante um espaço diferenciado de aprendizagem, que faz uso de estratégias acessíveis, como afirma 
Baptista (2011, p. 71) ao indicar que se torna necessário "reconhecer que, além das diretrizes gerais para a organização das salas de recursos, é fundamental garantir espaço de criação de delineamentos para esse serviço em função de características específicas de cada contexto".

Dessa forma, a Lei Brasileira de Inclusão (LBI) corrobora com esses documentos consultados. Essa lei assegurou a educação como um direito para todos e reiterou o caráter institucional ao Atendimento Educacional Especializado, assim como os demais serviços e adaptações razoáveis, para atender às características dos estudantes com deficiência, promovendo assim uma conquista e o exercício de sua autonomia (BRASIL, 2015). A partir de uma ótica reflexiva, pertinente ao movimento contemporâneo dado pelas leis e diretrizes consultadas e apresentadas nessa seção, entende-se que a oferta de recursos educacionais acessíveis torna-se um modo de (re)pensar o mundo que valoriza a educação equânime, onde se considera que todos são capazes de aprender, independente de sua condição.

\subsection{Jogos e materiais concretos: possibilidades para aprender Matemática}

As dificuldades dos estudantes na Matemática são as mais diversas e variam de sujeito para sujeito, sob a perspectiva do professor e sob a perspectiva do estudante, conforme indicam os estudos de Correa e MacLean (1999), Tatto e Scapin (2004), Santos (2009), Silveira (2011), Pacheco e Andreis (2018), entre outros. Nessa mesma perspectiva, nota-se que a escola e, em especial, o professor, durante o seu ofício, busquem desenvolver formas de superação das dificuldades. Com isso, almeja-se que a escola possa se tornar um espaço propício para que o estudante tenha condições para refletir e construir conhecimentos. Existem diversas maneiras de pensar na transformação do fazer docente, e entendemos que a utilização de jogos e materiais concretos, em sala de aula, possa ser uma ação desenvolvedora de potencial aprendizagem, quando inseridas no planejamento pedagógico do professor.

Sobre jogos, Oliveira, Trindade e Robaina (2018, p. 469) afirmam que:

Os jogos estimulam o raciocínio lógico, facilitam a concentração, desenvolvem conceitos matemáticos e a ortografia desafiando o aluno a construir estratégias e soluções para os desafios propostos. O educador deve buscar e desenvolver atividades que potencializem as reações cerebrais para que o processo de ensinoaprendizagem seja prazeroso, provocando mudanças quantitativas e qualitativas nas sinapses, resultando no melhor funcionamento cerebral. Para a neurociência não há pessoas incapaz de aprender ( $\mathrm{sic}$ ), o que existe, são cérebros com ritmos neurais diferentes que necessitam de mais estímulos e os processam de forma mais lenta.

Um dos propósitos da utilização dos jogos é convidar o estudante para participar da aula de forma mais ativa, pois aprender, de acordo com Tiellet et al. (2007, p. 2), "é uma atividade que acontece no aluno e que é realizada por ele. As pessoas não podem aprender umas pelas outras". Enfatizamos que, nessa perspectiva, o estudante se torna o protagonista no processo de aprendizagem, no qual o professor assume um papel de mediador entre o sujeito e o 
conhecimento, proporcionando momentos em que serão utilizadas as ferramentas necessárias para que a construção do conhecimento deste estudante possa ocorrer.

Além disso, a partir do jogo e do material concreto, a ação de brincar pode contribuir no aprendizado, o qual também pode ter influência sobre as demais ações do sujeito, sendo esses potenciais estruturantes para o desenvolvimento das ideias matemáticas. $\mathrm{O}$ uso desses aportes em sala de aula oportuniza que o estudante se sinta mais à vontade, e que a aprendizagem distancie-se de um contexto repetitivo e de aplicação de técnicas e fórmulas, sendo a ação e a estratégia desenvolvidas pelo estudante um potencial elemento para a aprendizagem. Com isso, os jogos/materiais concretos podem oportunizar aos estudantes momentos para alguma aprendizagem, cabendo ao professor, a partir de seu uso, possibilitar que a sala de aula seja um espaço com potencial para a construção e ressignificação de saberes.

A reflexão do parágrafo anterior converge ao que Fiorentini e Miorim (1990, p. 6) refletem:

Ao aluno deve ser dado o direito de aprender. Não um "aprender" mecânico, repetitivo, de fazer sem saber o que faz e por que faz. Muito menos um "aprender" que se esvazia em brincadeiras. Mas um aprender significativo do qual o aluno participe raciocinando, compreendendo, reelaborando o saber historicamente produzido e superando, assim, sua visão ingênua, fragmentada e parcial da realidade. Em outro momento, o mais importante não será o material, mas sim, a discussão e resolução de uma situação problema ligada ao contexto do aluno, ou ainda, à discussão e utilização de um raciocínio mais abstrato.

Assim, a partir das leituras sobre a temática desta seção, entende-se que a aprendizagem não deva ser necessariamente consequência de um ato repetitivo, mas sim, o resultado de ações que tenham relação entre os conceitos tratados em sala de aula e àqueles subjacentes ao momento do jogo ou uso de materiais concretos. Ou seja, entendemos que, na forma de trabalho proposta pelo professor, seja necessário abordar temas que estejam em sintonia aos mencionados em sala de aula sem deixar de considerar a estrutura de raciocínio implícita no ato de jogar.

\section{Metodologia de trabalho: materiais e métodos}

Os jogos e atividades apresentados neste trabalho foram inspirados em Smole et al. (2008). Tomando-se como base esse referencial, elaboramos e utilizamos ao longo do PIBID uma coleção de jogos e materiais concretos, permeados com atividades. Priorizou-se na execução da proposta uma metodologia de trabalho que enfatizasse reflexões para além da Matemática vista de forma reducional e exclusiva, como conceitos e exercícios. Em diversos momentos, durante a realização das atividades, foram feitas intervenções no formato de perguntas aos estudantes, sendo estes convidados à reflexão: "E se...?" ou "Por que isso acontece?", a fim de oportunizar aos participantes das atividades momentos de reflexão e, com os quais, pudessem contribuir para a construção de conceitos e saberes que estavam em estudo.

As atividades do projeto PIBID ocorreram no ano de 2019, no contexto do Ensino Médio, no Colégio de Aplicação, da Universidade Federal do Rio Grande do Sul, onde os estudantes já 
tinham acesso aos "laboratórios de ensino" com aulas oferecidas no turno inverso das aulas regulares. Os laboratórios de ensino são espaços de aprendizagem nos quais os estudantes que apresentam algum tipo de dificuldade cognitiva, ou que desejam aprofundar seus conhecimentos sobre uma área de conhecimento específica, são convidados a participar para possibilitar a ampliação do seu sistema conceitual referente às dificuldades apresentadas. Nesse sentido, pensou-se em um conjunto de ações que pudessem ser aplicadas no âmbito do atendimento educacional especializado (AEE) e que fossem mais convidativas ao trabalho com os estudantes público-alvo da Educação Especial. Essas atividades relacionadas à Matemática foram planejadas e desenvolvidas integralmente no contexto do projeto PIBID.

Os participantes foram dois estudantes do Ensino Médio - um do segundo ano e outro do terceiro ano -, etapa de interesse do bolsista do projeto PIBID. Por isso, a seleção dos estudantes que participariam das atividades inerentes ao projeto PIBID ocorreu anterior à chegada do bolsista, pois ambos os participantes, público-alvo da Educação Especial, já frequentavam o espaço de atendimento.

As atividades mencionadas nesse texto foram realizadas em pequenos grupos, na sua maioria realizada com os dois estudantes presentes, com a atuação presencial de um bolsista do projeto PIBID - Matemática. Destacamos que a participação de um bolsista do PIBID surgiu do interesse desse estudante, de Licenciatura em Matemática, que se sentiu desafiado a vivenciar situações diferenciadas daquelas já experienciadas em seu currículo. A professora de Educação Especial acolheu a proposta e considerou construtiva a oportunidade de ter um estudante da Licenciatura em Matemática interessado em estabelecer essa parceria, visto que a articulação entre a área e o ensino regular está prevista nas normativas e pode qualificar $o$ trabalho desenvolvido no atendimento. A partir dessa interlocução ocorreram os atendimentos na sala de recursos da escola, os quais foram permeados por atividades que fizeram o uso dos jogos e materiais concretos, e que são apresentados no Quadro 1.

Os jogos foram preparados/organizados pelo bolsista com materiais de fácil acesso, em sua maioria construídos com papel, tesoura, papelão e canetas coloridas. Ao todo foram preparados/organizados onze materiais, que foram subdivididos em três eixos (Estatística, Trigonometria e Geometria). Além desses materiais preparados pelo bolsista, utilizou-se, também, os do laboratório de ensino do colégio. A Figura 1 mostra, a título de exemplo, o “Dominó Matemático" que foi elaborado e utilizado nas atividades presenciais no AEE. 
Figura 1 - Layout das peças do "Dominó Matemático".

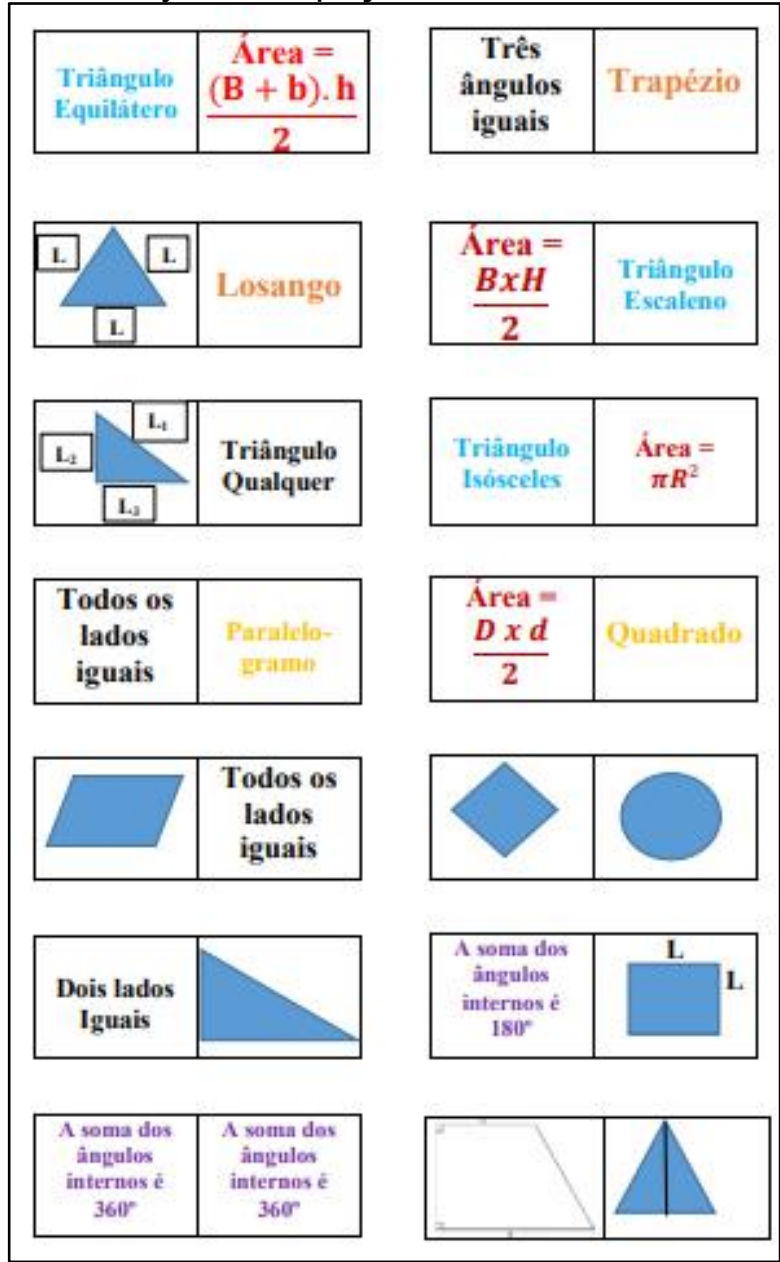

Fonte: Disponível em: https://www.ufrgs.br/pibid-mat2018/aulas PIBID Site/CAP/anexo1 t12.pdf. Acesso em: 20 mar. 2020.

Os materiais foram utilizados em sintonia com os conceitos desenvolvidos na sala de aula regular, bem como no espaço da Educação Especial, conciliando os espaços de aprendizagem vivenciados pelos estudantes. O Quadro 1 apresenta, de modo sintético, os eixos, os jogos ou materiais e suas características, sendo possível consultar, no site ${ }^{1}$ do projeto PIBID - Matemática, os planejamentos em detalhes, desde o objetivo até a descrição das atividades.

Quadro 1 - Jogos/materiais concretos e suas características.

\begin{tabular}{|c|c|c|}
\hline Eixo & $\begin{array}{c}\text { Nome do jogo } \\
\text { ou material }\end{array}$ & Características \\
\hline Estatística & $\begin{array}{l}\text { Tabuleiro com } \\
\text { Times }\end{array}$ & $\begin{array}{l}\text { Característica do material: Esse jogo é um jogo de tabuleiro no qual há } 36 \\
\text { quadrados organizados em seis linhas e seis colunas. O estudante dispõe de dois } \\
\text { dados de cores diferentes para jogar, sendo que suas direções de movimento são } \\
\text { distintas (um dado percorre o tabuleiro na horizontal e o outro dado percorre o } \\
\text { tabuleiro na vertical). } \\
\text { Objetivo: Realizar uma introdução aos cálculos de probabilidade em eventos } \\
\text { experimentais aleatórios. } \\
\text { Assuntos de Matemática explorados com o material: Cálculo de probabilidade } \\
\text { de eventos aleatórios. }\end{array}$ \\
\hline
\end{tabular}

${ }^{1}$ Disponível em: https://www.ufrgs.br/pibid-mat2018/. Acesso em: maio 2020. 


\begin{tabular}{|c|c|c|}
\hline Estatística & UNO & $\begin{array}{l}\text { Característica do material: Jogo UNO de cartas. O baralho é composto por } \\
\text { quatro tipos de cartas, agrupados por cores distintas e números de } 0 \text { a } 9 \text {. } \\
\text { Objetivo: Inferir sobre eventos probabilísticos envolvendo a retirada de cartas do } \\
\text { baralho, a partir de determinada característica (números e/ou cores). } \\
\text { Assuntos de Matemática explorados com o material: Identificação de espaços } \\
\text { amostrais, variáveis quantitativas e de interesse, cálculo de probabilidade de } \\
\text { eventos aleatórios. }\end{array}$ \\
\hline Estatística & $\begin{array}{l}\text { Brincando com } \\
\text { Estatística }\end{array}$ & $\begin{array}{l}\text { Característica do material: Jogo de tabuleiro no qual as casas do tabuleiro são } \\
\text { divididas entre "desafios" e "curiosidades", ambos relacionados à estatística e } \\
\text { probabilidade. O estudante joga um dado e avança o número de casas } \\
\text { correspondentes; caso erre o desafio, retorna para a casa de origem. No tabuleiro } \\
\text { há "Casas curiosidades", as quais são casas "bônus", onde são apresentados } \\
\text { fatos históricos que envolvem estatística. } \\
\text { Objetivo: Identificar as variáveis de interesse no exercício, as quais podem ser } \\
\text { informações adicionais não necessárias para o cálculo numérico. } \\
\text { Assuntos de Matemática explorados com o material: Identificação de espaços } \\
\text { amostrais, cálculo de probabilidade de eventos aleatórios. }\end{array}$ \\
\hline Trigonometria & $\begin{array}{c}\text { Prancha } \\
\text { Trigonométrica }\end{array}$ & $\begin{array}{l}\text { Característica do material: Material produzido que apresenta os valores de } \\
\text { cosseno e seno de ângulos, sendo possível constatar os valores das funções } \\
\text { trigonométricas seno e cosseno nos quatro quadrantes. } \\
\text { Objetivo: Comparar representações com as funções seno e cosseno, no plano } \\
\text { cartesiano. } \\
\text { Assuntos de Matemática explorados com o material: Valores das funções seno } \\
\text { e cossenos dos ângulos notáveis. }\end{array}$ \\
\hline Trigonometria & $\begin{array}{l}\text { Batalha Naval } \\
\text { Circular }\end{array}$ & $\begin{array}{l}\text { Característica do material: Jogo produzido com semelhança ao jogo de batalha } \\
\text { naval, porém, ao invés de coordenadas cartesianas com letras e números, são } \\
\text { utilizadas coordenadas polares indicadas por ângulos e raios. As posições das } \\
\text { pessoas são colocadas nas interseções das circunferências com os referidos } \\
\text { ângulos. Os ângulos variam de } 30^{\circ} \text { em } 30^{\circ} \text { e há três círculos concêntricos; para } \\
\text { determinar o local é necessário indicar uma medida de ângulo e uma medida de } \\
\text { raio. } \\
\text { Objetivo: Auxiliar na compreensão sobre ângulos complementares, suplementares } \\
\text { e equivalentes, além de oportunizar uma discussão sobre a representação dos } \\
\text { ângulos em radianos. } \\
\text { Assuntos de Matemática explorados com o material: Identificação dos ângulos } \\
\text { (graus e radianos) no círculo trigonométrico. }\end{array}$ \\
\hline Trigonometria & Trigonometrilha & $\begin{array}{l}\text { Característica do material: Jogo de tabuleiro no qual se faz necessário avançar } \\
\text { casas ao longo de uma trilha a partir do resultado obtido no lançamento de um } \\
\text { dado. Cada casa apresenta uma expressão diferente envolvendo cálculos } \\
\text { trigonométricos e, ao acertar o resultado, o estudante avança na trilha do tabuleiro, } \\
\text { caso erre, retrocede. } \\
\text { Objetivo: Fomentar a discussão e estudo de funções seno e cosseno a partir de } \\
\text { um jogo lúdico e dinâmico. } \\
\text { Assuntos de Matemática explorados com o material: Identificação das } \\
\text { características das funções seno e cosseno. }\end{array}$ \\
\hline Trigonometria & Teodolito & $\begin{array}{l}\text { Característica do material:Teodolito de madeira disponibilizado pela escola. } \\
\text { Objetivo: Inferir, a partir do uso do teodolito e de relações trigonométricas no } \\
\text { triângulo retângulo, a altura de objetos inacessíveis. } \\
\text { Assuntos de Matemática explorados com o material: Cálculo da altura de um } \\
\text { triângulo retângulo a partir da tangente. }\end{array}$ \\
\hline Trigonometria & GeoGebra & $\begin{array}{l}\text { Característica do material: Computadores com acesso à internet disponibilizados } \\
\text { pela escola. } \\
\text { Objetivo: Construir e observar, a partir de uma visualização gráfica virtual, os } \\
\text { gráficos das funções seno e cosseno. } \\
\text { Assuntos de Matemática explorados com o material: Representações gráficas } \\
\text { das funções trigonométricas seno e cosseno. }\end{array}$ \\
\hline
\end{tabular}




\begin{tabular}{|c|c|c|}
\hline Geometria & $\begin{array}{c}\text { Triângulos de } \\
\text { E.V.A. }\end{array}$ & $\begin{array}{l}\text { Característica do material: Triângulos confeccionados em acetato-vinilo de } \\
\text { etileno (E.V.A.). } \\
\text { Objetivo: Construir relações entre as características das figuras planas em estudo. } \\
\text { Assuntos de Matemática explorados com o material: Identificação de } \\
\text { características das figuras planas. }\end{array}$ \\
\hline Geometria & $\begin{array}{c}\text { Dominó } \\
\text { Geométrico }\end{array}$ & $\begin{array}{l}\text { Característica do material: Com base no jogo de dominó tradicional, os } \\
\text { participantes têm como possibilidades de encaixe, para as peças criadas, as } \\
\text { características das figuras geométricas, bem como relações matemáticas e } \\
\text { definições. } \\
\text { Objetivo: Construir relações entre as características das figuras planas em estudo. } \\
\text { Assuntos de Matemática explorados com o material: Identificação de } \\
\text { características das figuras planas. }\end{array}$ \\
\hline Geometria & Geoplano & $\begin{array}{l}\text { Característica do material: Geoplanos disponibilizados pela escola. } \\
\text { Objetivo: Construir relações a partir das características das figuras planas e, com } \\
\text { base nas observações sobre as figuras geométricas construídas no Geoplano, } \\
\text { determinar a área de figuras. } \\
\text { Assuntos de Matemática explorados com o material: Identificação de } \\
\text { características e cálculo da área de figuras planas. }\end{array}$ \\
\hline Geometria & $\begin{array}{l}\text { Área da Pele do } \\
\text { Corpo Humano }\end{array}$ & $\begin{array}{l}\text { Característica do material: Fita métrica disponibilizada pela escola. } \\
\text { Objetivo: Inferir, a partir de aproximações por meio de figuras geométricas, um } \\
\text { valor aproximado para a área do corpo humano. } \\
\text { Assuntos de Matemática explorados com o material: Identificação de } \\
\text { características e cálculo da área de figuras planas. }\end{array}$ \\
\hline Geometria & Quem sou eu? & $\begin{array}{l}\text { Característica do material: Fichas com perguntas e características a respeito de } \\
\text { objetos da geometria. } \\
\text { Objetivo: Determinar, a partir de dicas e definições, qual objeto geométrico } \\
\text { encontra-se em discussão na rodada. } \\
\text { Assuntos de Matemática explorados com o material: Identificação de } \\
\text { características das figuras planas. }\end{array}$ \\
\hline Geometria & $\begin{array}{l}\text { Sólidos de } \\
\text { Acrílico }\end{array}$ & $\begin{array}{l}\text { Característica do material: Sólidos de acrílico disponibilizados pela escola. } \\
\text { Objetivo: Inferir, a partir do manuseio dos sólidos de acrílico, relações para os } \\
\text { objetos geométricos em estudo, tais como volume. } \\
\text { Assuntos de Matemática explorados com o material: Identificação de } \\
\text { características e cálculo de área e volume de sólidos geométricos. }\end{array}$ \\
\hline
\end{tabular}

Fonte: Baseado nas atividades apresentadas em https://www.ufrgs.br/pibid-mat2018/. Acesso em: 20 mar. 2020.

Ao longo das aulas, as quais ocorreram semanalmente com duração de 1 hora e 30 minutos cada, foram observadas as reações e ações dos estudantes participantes dos momentos. Entende-se que nosso olhar sobre tais ações esteja ancorado com o proposto por Bogdan e Biklen (1994), os quais apresentam como características para um estudo de cunho qualitativo: "a investigação qualitativa é descritiva" (ibidem, p. 48), "os investigadores qualitativos interessam-se mais pelo processo do que simplesmente pelos resultados ou produtos" (ibidem, p. 50) e "o significado é de importância vital na abordagem qualitativa" (ibidem, p. 50). A partir disso, compreende-se que, ao observar e analisar como os dois estudantes participantes se envolveram com as atividades propostas, além de constatar se os objetivos pensados por nós estavam sendo de alguma foram alcançados por eles, mobilizou-se de forma articulada e conjunta um trabalho entre o AEE desenvolvido na escola com o projeto de iniciação em docência em Matemática.

Diante disso foram produzidas pelo bolsista, também para efeitos de registros junto ao órgão de fomento ao projeto, anotações em um "diário de campo" (FIORENTINI; LORENZATO, 
2009, p. 118), sendo essas utilizadas na produção dos relatórios, os quais resgatam os objetivos de cada atividade e refletem a forma e intensidade que os objetivos foram contemplados. Os relatórios produzidos estão publicados no site do projeto PIBID - Matemática, e são produtos que derivam de uma escrita reflexiva, ocorrida após a prática experimental de ensino, baseada em observações sobre elementos que oportunizaram a riqueza do momento pedagógico. A próxima seção apresenta e reflete de forma geral sobre as práticas ocorridas, relacionando-as com os aportes teóricos apresentados no texto.

\section{Reflexões pós-experiência: algumas discussões}

De forma preliminar, entendemos que a elaboração e utilização dos jogos e materiais concretos contribuíram para o processo de aprendizagem dos estudantes participantes do projeto PIBID - Matemática, considerando as observações feitas tanto na sala de aula regular quanto no AEE. Observou-se que os estudantes ampliaram seu interesse pelos conceitos de Matemática em debate após a utilização dos diversos materiais. Também foi observada a ampliação da participação dos estudantes por meio de questionamentos e inserção em atividades em grupo na sala de aula regular, o que não ocorria anteriormente. As estratégias de intervenção adotadas oportunizaram aos estudantes uma interlocução com a Matemática, que proporcionou aos estudantes uma visão distinta da Matemática, mostrando a Matemática por meio de jogos e materiais concretos, os quais não faziam, até então, parte das aulas de Matemática. Os jogos e demais materiais utilizados desafiaram os estudantes participantes do projeto. Então, percebe-se que a atividade foi, ao mesmo tempo, lúdica e com potencial para a construção de ideias.

No Quadro 2, apresentamos um recorte com os estudantes presentes na atividade, os objetivos da atividade e nossas observações, a partir das ações dos estudantes, na tentativa de alcançar os objetivos. Os objetivos construídos para cada atividade foram organizados de acordo com os seguintes critérios: Obj-est - objetivo relacionado com o desenvolvimento de habilidades matemáticas por parte dos estudantes, as quais julgávamos pertinentes e aderentes ao assunto em debate nos encontros; e Obj-prof - objetivo relacionado com as ações do bolsista ministrante que conduzia os encontros com os estudantes participantes do projeto.

Menciona-se que nossa análise se concentrou em apresentar resultados e reflexões gerais provenientes do conjunto de atividades ocorridas, uma vez que nosso foco é mostrar como o projeto PIBID - Matemática e o AEE atuaram de forma conjunta e simbiótica no espaço escolar em sintonia com as proposições normativas para a área que enfatizam esta parceria - e de alguma forma contribuíram na formação dos estudantes participantes. 


\section{Quadro 2 - Objetivos e observações a partir das ações dos estudantes, constatados por meio da} prática.

\begin{tabular}{|c|c|c|c|}
\hline $\begin{array}{l}\text { Material } \\
\text { utilizado }\end{array}$ & $\begin{array}{l}\text { Estudantes do } \\
\text { Ensino Médio } \\
\text { participantes }\end{array}$ & $\begin{array}{l}\text { Objetivos a serem } \\
\text { alcançados com as } \\
\text { atividades* }\end{array}$ & $\begin{array}{l}\text { Observações a partir das ações } \\
\text { dos estudantes }\end{array}$ \\
\hline $\begin{array}{c}\text { Triângulos de } \\
\text { E.V.A. }\end{array}$ & $\begin{array}{l}1 \text { estudante do } \\
2^{\circ} \text { ano } \\
1 \text { estudante do } \\
3^{\circ} \text { ano }\end{array}$ & $\begin{array}{l}\text { Obj-est: Identificar e classificar os } \\
\text { diferentes tipos de triângulos a } \\
\text { partir de observações e medições } \\
\text { de lados dos triângulos e ângulos. } \\
\text { Obj-prof: Oportunizar a construção } \\
\text { de relações entre as características } \\
\text { das figuras planas em estudo por } \\
\text { meio do material confeccionado em } \\
\text { E.V.A. }\end{array}$ & $\begin{array}{l}\text { Conhecimento do estudante e } \\
\text { compreensão de suas dificuldades para } \\
\text { aulas posteriores. Durante a atividade, } \\
\text { articulou-se uma abordagem para } \\
\text { desmistificar a Matemática como algo que } \\
\text { não pode ser simples ou que é chato. }\end{array}$ \\
\hline $\begin{array}{l}\text { Tabuleiro de } \\
\text { Times }\end{array}$ & $\begin{array}{l}1 \text { estudante do } \\
3^{\circ} \text { ano }\end{array}$ & $\begin{array}{l}\text { Obj-est: Revisar as relações } \\
\text { trigonométricas e ângulos. } \\
\text { Obj-prof: Elaborar atividades mais } \\
\text { próximas ao estudante trazendo } \\
\text { jogos com conteúdos do cotidiano } \\
\text { e que o estudante conheça para } \\
\text { que assim possa visualizar } \\
\text { conceitos que não são } \\
\text { aparentemente notórios quando se } \\
\text { aprende apenas com a matéria. } \\
\text { Realizar uma introdução aos } \\
\text { cálculos de probabilidade em } \\
\text { eventos experimentais aleatórios. }\end{array}$ & $\begin{array}{l}\text { Analisaram-se as dificuldades que o } \\
\text { estudante ainda apresentava e trabalhou- } \\
\text { se na perspectiva de aprendizagem } \\
\text { destas lacunas do ensino de Matemática. } \\
\text { O estudante apresentou-se animado pela } \\
\text { experiência nova com jogos e o } \\
\text { dinamismo que a atividade proporcionou. } \\
\text { Baseado na repetição dos eventos dos } \\
\text { dados, ele começou a compreender quais } \\
\text { os times mais difíceis de alcançar via jogo } \\
\text { e criou uma definição a partir desses } \\
\text { resultados, e percebeu que era possível } \\
\text { para todos os outros eventos também. }\end{array}$ \\
\hline Teodolito & $\begin{array}{l}1 \text { estudante do } \\
2^{\circ} \text { ano }\end{array}$ & $\begin{array}{l}\text { Obj-est: Qualificar a compreensão } \\
\text { de conceitos da trigonometria, mais } \\
\text { especificamente, da relação } \\
\text { trigonométrica da tangente. } \\
\text { Obj-prof: Trazer uma perspectiva } \\
\text { diferente da sala de aula levando } \\
\text { uma situação-problema para se } \\
\text { calcular a altura de objetos. }\end{array}$ & $\begin{array}{l}\text { Revisão do conteúdo por meio de } \\
\text { atividades novas e interativas, trazendo } \\
\text { música para o preenchimento de valores } \\
\text { dos ângulos notáveis. O estudante não } \\
\text { demonstrava ter tanto interesse em } \\
\text { Matemática, mas apresentou entusiasmo } \\
\text { ao ver que a atividade seria no pátio e } \\
\text { utilizando objetos diferentes dos já } \\
\text { usados em sala de aula. Quando } \\
\text { precisou calcular a altura de uma árvore, } \\
\text { a relação com o conteúdo emergiu, } \\
\text { lembrando das relações trigonométricas } \\
\text { seno, cosseno e tangente e identificando } \\
\text { qual seria a mais apropriada para o } \\
\text { contexto. }\end{array}$ \\
\hline Teodolito & $\begin{array}{c}1 \text { estudante do } \\
3^{\circ} \text { ano }\end{array}$ & $\begin{array}{l}\text { Obj-est: Qualificar a compreensão } \\
\text { de conceitos da trigonometria, mais } \\
\text { especificamente, da relação } \\
\text { trigonométrica da tangente. } \\
\text { Obj-prof: Revisar as relações } \\
\text { trigonométricas e ângulos para } \\
\text { compreender se a dificuldade dos } \\
\text { estudantes pode estar ligada à } \\
\text { ausência de estudo no turno que } \\
\text { não estão no colégio ou o } \\
\text { entendimento do conteúdo. }\end{array}$ & $\begin{array}{l}\text { Houve interesse do estudante ao se levar } \\
\text { um jogo cujo assunto era a matéria que } \\
\text { ele aprendia dentro de uma sala apenas } \\
\text { por fórmulas e conceitos, sendo um } \\
\text { ambiente de aprendizado além da sala de } \\
\text { aula. O estudante já tinha conhecimento } \\
\text { da matéria, mas ainda apresentava } \\
\text { dificuldade acerca do assunto. Com } \\
\text { algumas estratégias com música, ficou } \\
\text { mais perceptível para o estudante } \\
\text { relacionar conceitos inerentes para a } \\
\text { atividade. }\end{array}$ \\
\hline UNO & $\begin{array}{c}1 \text { estudante do } \\
3^{\circ} \text { ano }\end{array}$ & $\begin{array}{l}\text { Obj-est: Conjecturar e testar } \\
\text { eventos probabilísticos envolvendo } \\
\text { a retirada de cartas do baralho, a } \\
\text { partir de determinada característica } \\
\text { (números e/ou cores). } \\
\text { Obj-prof: Apresentar por meio de } \\
\text { abordagens alternativas, conceitos } \\
\text { matemáticos já vistos pelos } \\
\text { estudantes na sala de aula regular. }\end{array}$ & $\begin{array}{l}\text { Foram retomados, por meio do jogo UNO, } \\
\text { conceitos de multiplicação de frações, } \\
\text { devido às dificuldades apresentadas pelo } \\
\text { estudante nos últimos atendimentos. } \\
\text { Assim, produziu-se em uma atividade, de } \\
\text { maneira mais prática e visual, a } \\
\text { probabilidade de certos eventos e como } \\
\text { eles podem não acontecer. }\end{array}$ \\
\hline $\begin{array}{l}\text { Batalha Naval } \\
\text { Circular e } \\
\text { Brincando com }\end{array}$ & $\begin{array}{l}1 \text { estudante do } \\
2^{\circ} \text { ano } \\
1 \text { estudante do }\end{array}$ & $\begin{array}{l}\text { Obj-est: Aumentar a compreensão } \\
\text { sobre ângulos complementares, } \\
\text { suplementares, equivalentes e }\end{array}$ & $\begin{array}{l}\text { Alcançamos todos os objetivos e, com } \\
\text { eles, não só potencializamos conceitos } \\
\text { matemáticos, mas também um trabalho }\end{array}$ \\
\hline
\end{tabular}




\begin{tabular}{|c|c|c|c|}
\hline Estatística & $3^{\circ}$ ano & $\begin{array}{l}\text { suas representações em radianos. } \\
\text { Identificar as variáveis de interesse } \\
\text { no exercício que pudessem ser } \\
\text { informações adicionais não } \\
\text { necessárias para o cálculo } \\
\text { numérico. } \\
\text { Obj-prof: Utilizar o círculo } \\
\text { trigonométrico na forma de um jogo } \\
\text { interativo com a finalidade de } \\
\text { construir a noção do círculo } \\
\text { trigonométrico. Oportunizar um } \\
\text { debate sobre conceito e } \\
\text { curiosidades envolvendo estatística } \\
\text { e probabilidade. }\end{array}$ & $\begin{array}{l}\text { com a socialização dos estudantes. Os } \\
\text { estudantes apresentaram mais facilidade } \\
\text { no que diz respeito a ângulos radianos, } \\
\text { fazendo relação do que aprendem em } \\
\text { sala de aula com as atividades } \\
\text { desenvolvidas no AEE, assim, } \\
\text { recordando de frases e conceitos em } \\
\text { estudo na sala de aula regular. }\end{array}$ \\
\hline $\begin{array}{l}\text { Trigonometrilha } \\
\text { e Brincando com } \\
\text { Estatística }\end{array}$ & $\begin{array}{c}1 \text { estudante do } \\
2^{\circ} \text { ano } \\
1 \text { estudante do } \\
3^{\circ} \text { ano }\end{array}$ & $\begin{array}{l}\text { Obj-est: Estudar as características } \\
\text { das funções seno e cosseno a } \\
\text { partir de um jogo lúdico e dinâmico. } \\
\text { Identificar as variáveis de interesse } \\
\text { no exercício que pudessem ser } \\
\text { informações adicionais não } \\
\text { necessárias para o cálculo } \\
\text { numérico. } \\
\text { Obj-prof: Fazer o uso de materiais } \\
\text { lúdicos para realizar jogos e } \\
\text { brincadeiras. Oportunizar um } \\
\text { debate sobre conceito e } \\
\text { curiosidades envolvendo estatística } \\
\text { e probabilidade. }\end{array}$ & $\begin{array}{l}\text { Recordamos alguns momentos em que } \\
\text { usamos o Teodolito, em atividades } \\
\text { anteriores, nas quais tínhamos que usar a } \\
\text { tangente do ângulo dado a fim de } \\
\text { solucionar os problemas do jogo. Agora, } \\
\text { ângulos radianos não eram problema aos } \\
\text { estudantes, pois apresentaram domínio } \\
\text { em transformar ângulos de graus para } \\
\text { radianos e vice-versa. }\end{array}$ \\
\hline $\begin{array}{c}\text { Prancha } \\
\text { Trigonométrica }\end{array}$ & $\begin{array}{c}1 \text { estudante do } \\
2^{\circ} \text { ano } \\
1 \text { estudante do } \\
3^{\circ} \text { ano }\end{array}$ & $\begin{array}{l}\text { Obj-est: Observar, a partir da } \\
\text { manipulação do objeto concreto, os } \\
\text { valores do cosseno, seno e } \\
\text { tangente de um triângulo retângulo } \\
\text { inserido em um círculo } \\
\text { trigonométrico. } \\
\text { Obj-prof: Fazer o uso de materiais } \\
\text { lúdicos como jogos de tabuleiros } \\
\text { para a construção do } \\
\text { conhecimento. }\end{array}$ & $\begin{array}{l}\text { Transformamos de maneira lúdica e } \\
\text { dinâmica o estudo de ângulos, } \\
\text { esclarecendo as dúvidas ainda pendentes } \\
\text { da aula anterior. Além disso, notamos } \\
\text { que os estudantes estavam ficando à } \\
\text { vontade com a abordagem do assunto } \\
\text { devido a suas observações no construído } \\
\text { no GeoGebra, o que nos deixou com } \\
\text { mais segurança na continuidade sobre a } \\
\text { forma de condução da abordagem. } \\
\text { Observamos que os estudantes } \\
\text { compreenderam com mais clareza o } \\
\text { significado dos valores do seno, cosseno } \\
\text { e tangente. }\end{array}$ \\
\hline GeoGebra & $\begin{array}{c}1 \text { estudante do } \\
2^{\circ} \text { ano } \\
1 \text { estudante do } \\
3^{\circ} \text { ano }\end{array}$ & $\begin{array}{l}\text { Obj-est: Construir, por meio da } \\
\text { investigação dos ângulos e } \\
\text { medidas dos lados de um triângulo, } \\
\text { uma percepção de mudanças que } \\
\text { são geradas nas leis do seno e } \\
\text { cosseno. } \\
\text { Obj-prof: Fazer uso do recurso } \\
\text { computacional para oportunizar } \\
\text { momentos de construção do } \\
\text { conhecimento acerca do assunto } \\
\text { para os estudantes. }\end{array}$ & $\begin{array}{l}\text { Realizamos investigações, e } \\
\text { conseguimos observar que os estudantes } \\
\text { não estavam tão familiarizados com o } \\
\text { GeoGebra como se esperava e, assim, } \\
\text { não abstraiam a partir do arquivo } \\
\text { contruído no Geogebra como o esperado. } \\
\text { Notamos que uma atividade prática com } \\
\text { a prancha trigonométrica foi mais } \\
\text { produtiva que no computador com o } \\
\text { auxílio do GeoGebra. }\end{array}$ \\
\hline $\begin{array}{c}\text { Dominó } \\
\text { Geométrico }\end{array}$ & $\begin{array}{c}1 \text { estudante do } \\
2^{\circ} \text { ano } \\
1 \text { estudante do } \\
3^{\circ} \text { ano }\end{array}$ & $\begin{array}{l}\text { Obj-est: Realizar uma revisão } \\
\text { sobre o tema áreas das figuras } \\
\text { planas por meio da utilização de } \\
\text { um jogo. } \\
\text { Obj-prof: Investigar com os } \\
\text { estudantes a relação entre áreas } \\
\text { das figuras planas de diferentes } \\
\text { objetos, tais como quadrados e } \\
\text { triângulos. }\end{array}$ & $\begin{array}{l}\text { Os estudantes questionaram e indagaram } \\
\text { um ao outro com suas opiniões e, em } \\
\text { seguida, chegaram à conclusão de que a } \\
\text { área seria calculada como base vezes } \\
\text { altura. Observamos a discussão dos } \\
\text { estudantes e gostamos do diálogo deles, } \\
\text { não havendo necessidade de } \\
\text { intervenções. }\end{array}$ \\
\hline Geoplano & $\begin{array}{l}1 \text { estudante do } \\
2^{\circ} \text { ano } \\
1 \text { estudante do } \\
3^{\circ} \text { ano }\end{array}$ & $\begin{array}{l}\text { Obj-est: Utilizar jogos lúdicos no } \\
\text { estudo de área e perímetro de } \\
\text { figuras planas. } \\
\text { Obj-prof: Abordar por meio de } \\
\text { ações sobre o material concreto a } \\
\text { noção de perímetro e área das }\end{array}$ & $\begin{array}{l}\text { Ao fazer o uso de materiais lúdicos, tais } \\
\text { como o Geoplano, para que os } \\
\text { estudantes pudessem criar uma } \\
\text { visualização das diferenças/semelhanças } \\
\text { entre área e perímetro, notou-se que a } \\
\text { ideia sobre o tema em estudo foi }\end{array}$ \\
\hline
\end{tabular}




\begin{tabular}{|c|c|c|c|}
\hline & & figuras planas. & $\begin{array}{l}\text { aperfeiçoada enquanto manipulávamos o } \\
\text { Geoplano. Nesse momento, também foi } \\
\text { debatida e criada a ideia de "unidade de } \\
\text { comprimento e unidade de área", as } \\
\text { quais, não aparentavam ser um elemento } \\
\text { necessário para os estudantes. }\end{array}$ \\
\hline $\begin{array}{c}\text { Área do Corpo } \\
\text { Humano }\end{array}$ & $\begin{array}{c}1 \text { estudante do } \\
2^{\circ} \text { ano } \\
1 \text { estudante do } \\
3^{\circ} \text { ano }\end{array}$ & $\begin{array}{l}\text { Obj-est: Obter uma medida } \\
\text { aproximada para a superfície de } \\
\text { pele no corpo humano por meio do } \\
\text { cálculo da área de figuras planas } \\
\text { exploradas nas aulas. } \\
\text { Obj-prof: Realizar atividades com } \\
\text { curiosidades históricas sobre } \\
\text { medições a partir das áreas de } \\
\text { figuras exploradas. Utilizar } \\
\text { elementos de interdisciplinaridade } \\
\text { que possam ter uma relação entre } \\
\text { fatos históricos e curiosidades que } \\
\text { envolvam a Matemática. }\end{array}$ & $\begin{array}{l}\text { Os estudantes mostraram-se } \\
\text { interessados nos fatores históricos } \\
\text { trazidos. Além disso, eles foram sempre } \\
\text { recebidos com atividades dinâmicas e/ou } \\
\text { jogos, tornando uma atividade } \\
\text { interessante para se trabalhar. Mesmo } \\
\text { com aproximações para as áreas de } \\
\text { figuras planas, os estudantes se } \\
\text { mostraram interessados, tanto na } \\
\text { aplicabilidade, quanto na atividade. } \\
\text { Percebemos como foi intrigante e } \\
\text { desafiador o modo com que os } \\
\text { estudantes buscavam em suas memórias } \\
\text { figuras planas mais próximas para suas } \\
\text { partes do corpo, para depois as usarem } \\
\text { no cálculo das áreas. }\end{array}$ \\
\hline Quem sou eu? & $\begin{array}{c}1 \text { estudante do } \\
2^{\circ} \text { ano } \\
1 \text { estudante do } \\
3^{\circ} \text { ano }\end{array}$ & $\begin{array}{l}\text { Obj-est: Relacionar as áreas e os } \\
\text { volumes de sólidos geométricos } \\
\text { com as figuras planas previamente } \\
\text { conhecidas. } \\
\text { Obj-prof: Oportunizar aos } \\
\text { estudantes o aperfeiçoamento de } \\
\text { conceitos de Matemática sobre } \\
\text { geometria por meio de uma } \\
\text { atividade lúdica com desafios e } \\
\text { brincadeiras. }\end{array}$ & $\begin{array}{l}\text { Tais atividades fizeram os estudantes } \\
\text { compreenderem as diferenças entre área } \\
\text { e volume de sólidos geométricos, e } \\
\text { também propor um momento } \\
\text { descontraído com uma atividade em que } \\
\text { os estudantes pudessem observar } \\
\text { propriedades destes sólidos abordados } \\
\text { em aula. Observamos que, a partir das } \\
\text { propriedades, os estudantes pensavam e } \\
\text { desenhavam esboços para se aproximar } \\
\text { do objeto estudado. }\end{array}$ \\
\hline $\begin{array}{l}\text { Sólidos de } \\
\text { Acrílico }\end{array}$ & $\begin{array}{c}1 \text { estudante do } \\
2^{\circ} \text { ano } \\
1 \text { estudante do } \\
3^{\circ} \text { ano }\end{array}$ & $\begin{array}{l}\text { Obj-est: Aperfeiçoar conceitos } \\
\text { matemáticos acerca de geometria } \\
\text { espacial com desafios e } \\
\text { brincadeiras. } \\
\text { Obj-prof: Explorar com os } \\
\text { estudantes a noção do volume de } \\
\text { sólidos geométricos relacionando } \\
\text { com as figuras planas. Mostrar a } \\
\text { relação de tamanho total, tamanho } \\
\text { ocupado e porcentagem, a partir da } \\
\text { manipulação dos objetos. }\end{array}$ & $\begin{array}{l}\text { Os estudantes mostraram-se ter menos } \\
\text { domínio em relação ao volume. Nesta } \\
\text { aula, observamos que os sólidos } \\
\text { utilizados chamaram a atenção dos } \\
\text { estudantes, parecendo uma total } \\
\text { novidade. Ficou explícita a diferença } \\
\text { produzida pelos estudantes envolvendo } \\
\text { área e volume dos sólidos geométricos. } \\
\text { Os estudantes, após a aplicação da } \\
\text { atividade, demonstraram ter } \\
\text { conhecimento de como obter o volume } \\
\text { dos sólidos, usando os sólidos de acrílico } \\
\text { e um copo medidor para comprovar suas } \\
\text { hipóteses. }\end{array}$ \\
\hline
\end{tabular}

Fonte: Baseado nos arquivos de planejamento elaborados pelo bolsista do projeto PIBID - Matemática disponíveis em: https://www.ufrgs.br/pibid-mat2018/. Acesso em: 20 mar. 2020.

A partir das informações apresentadas no Quadro 2, é possível refletir que as atividades realizadas no AEE, por meio do projeto PIBID, ocorreram com as seguintes características: (I) houve atividades que exigiram mais intervenção do bolsista ministrante, inclusive para que o estudante participante pudesse elaborar e articular argumentos matemáticos; (II) ocorreram situações em que se observou a construção de argumentos e inferências pelo próprio estudante, ocorrendo menos intervenção do bolsista; e (III) situações em que a intervenção ou mediação do ministrante das atividades diante dos estudantes, ocorreu de forma mínima. Nesse último termo, observou-se que os estudantes participantes construíram, articularam e organizaram formas de pensamento matemático com pouca necessidade de intervenção por parte do ministrante da aula. 
A partir das características (I), (II) e (III), entendemos que tenha sido plural e democrático o uso dos materiais concretos e jogos (Quadro 1), no âmbito do AEE. Ao mesmo tempo em que buscávamos atender às demandas educacionais, nosso objetivo também foi oportunizar aos estudantes momentos de protagonismo diante dos assuntos em estudo.

É importante ressaltar também que os professores de Matemática regentes destes estudantes solicitavam diversas demandas que poderiam ser desenvolvidas nos encontros do projeto no AEE. A título de exemplo, mencionamos que o estudante do $2^{\circ}$ ano do Ensino Médio participou de atividades que articulavam conceitos de trigonometria e aritmética, com progressão aritmética e progressão geométrica. Tais conceitos foram fundamentais para a elaboração das atividades propostas. Ao participar dos momentos no AEE, o estudante mencionado questionou sobre a possibilidade de também realizar com os colegas da aula regular a proposta, sendo esse encaminhamento refletido por parte dos professores.

A abordagem realizada na sala de recursos sinalizou, ainda, evolução acerca dos conceitos abordados, bem como avanços significativos na socialização dos participantes com seus pares e seus professores. Com as atividades realizadas durante o projeto, observou-se também um aumento no interesse dos estudantes participantes em estudar Matemática. A partir de relatos dos professores das aulas regulares foi possível perceber avanços nos momentos das aulas regulares, tanto em aspectos sobre avaliação, quanto de participação desses estudantes nas aulas. A Figura 2 mostra momentos das aulas do projeto, com a participação dos estudantes.

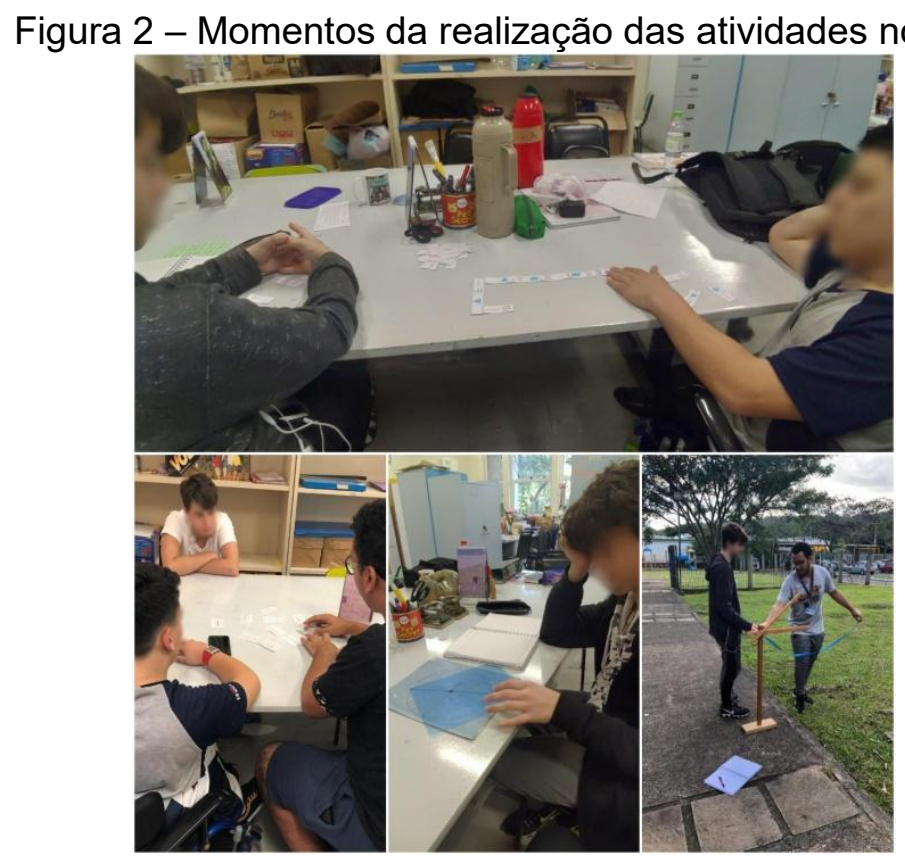

Fonte: Acervo dos autores (2019)

Para finalizar nosso exercício reflexivo a partir das atividades realizadas, reiteramos que essas tiveram alinhamento ao que se propõe na literatura apresenta na Seção 2.2 desse texto. Foi considerado desde o início das atividades que, a partir de ações sobre os materiais em uso, os 
estudantes pudessem conjecturar, testar, validar ou refutar ideias por meio da argumentação Matemática. Sob essa perspectiva, entendemos que tenha sido oportunizado o desenvolvimento do protagonismo dos envolvidos em construir ideias. Constatamos que os referenciais teóricos apresentados na seção 2.1 alinharam-se às ações ocorridas no projeto PIBID - Matemática no momento em que se refletiu e compreendeu a complexidade da oferta e das características que o projeto deveria ter para contemplar de alguma forma as demandas pré-existentes na escola. Por fim, destacamos que, no âmbito do AEE, os estudantes são atendidos de forma individualizada, possibilitando que o professor possa mapear e explorar suas dificuldades, por meio da análise e criação de estratégias acessíveis para esse público, tendo isso também ocorrido durante as atividades relacionadas ao projeto PIBID - Matemática.

\section{Considerações finais}

A experiência e a reflexão expostas nesse texto não denotam o fim do debate sobre a docência em espaços de $\mathrm{AEE}$, pelo contrário, mostram-nos que deve haver um movimento de continuidade e permanente discussão, que pode ser realizada em disciplinas na formação inicial de professores ou em projetos institucionalizados. Tal experiência, oportunizada pelo projeto PIBID, foi uma prática singular que, por meio da análises das aulas, observações e prática docente, tornou possível vivenciar momentos que permitiram refletir sobre a formação inicial docente e aspectos relacionados ao atendimento de estudantes público-alvo da Educação Especial. Pode-se destacar tal experiência, ainda, como espaço de autoformação que decorre das relações e trocas realizadas entre bolsista e demais professores, bem como, a partir da rede que se institui entre Universidade e Escola. Tal movimento enfatiza a importância e permanência de programas como o PIBID, a partir do qual se torna possível uma aproximação de futuros professores com a docência na Educação Básica.

A partir dos estudos nos materiais consultados, os quais serviram de fonte para a criação das atividades, percebeu-se que os estudantes envolviam-se com as propostas, tal como previamente planejado, e alcançavam, à sua maneira, os objetivos elencados, inclusive com a participação na construção de ideias e conceitos matemáticos. Este ponto nos fornece pistas acerca da potência da construção de um processo de aprendizagem que se constitui, prioritariamente, a partir da aposta na capacidade de aprender do estudante.

Como reflexão final, entende-se que, a partir dos relatórios produzidos como parte integrante das atividades do projeto PIBID, tenha ocorrido a realização do exercício de autoavaliação docente, que permitiu a qualificação dos planejamentos subsequentes. Ao longo do projeto, conseguiu-se observar e ter conhecimento sobre as singularidades e especificidades dos estudantes, tornando assim o planejamento das aulas um produto reflexivo. Por fim, valorizamos a ideia de que tais propostas desenvolvidas durante as atividades, e apresentadas no texto, possam 
ser aplicadas para além do espaço de AEE, sendo estendidas também para turmas regulares do Ensino Fundamental e do Ensino Médio.

\section{Agradecimentos}

À Coordenação de Aperfeiçoamento de Pessoal de Nível Superior (CAPES) pelo recurso financeiro disponibilizado por meio do Edital n 07/2018 para a execução subprojeto PIBID Matemática, no âmbito da Universidade Federal do Rio Grande do Sul.

\section{Referências}

BAPTISTA, C. R. Ação pedagógica e educação especial: a sala de recursos como prioridade na oferta de serviços especializados. Revista Brasileira de Educação Especial, v. 17, n. esp., p. 59-76, maio/ago. 2011. DOI: https://doi.org/10.1590/S1413-65382011000400006.

BOGDAN, R. C.; BIKLEN, S. K. Investigação qualitativa em educação. Trad.: ALVAREZ, Maria João; SANTOS, Sara Bahia dos; BAPTISTA, Telmo Mourinho. Porto/Portugal: Porto Editora, 1994.

BRABO, G. M. B. Formação docente inicial e o ensino ao aluno com deficiência em classe comum na perspectiva da educação inclusiva. 2013. 163 f. Tese (Doutorado em Educação) Programa de Pós-Graduação em Educação, Universidade Federal do Rio Grande do Sul, Porto Alegre, 2013.

BRASIL. Casa Civil. Lei № 4.024, de 20 de dezembro de 1961. Fixa as Diretrizes e Bases da Educação Nacional. Diário Oficial da União, Brasília/DF, 27 dez. 1961.

BRASIL. Casa Civil. Lei № 5.962, de 11 de agosto de 1971. Fixa Diretrizes e Bases para o ensino de $1^{\circ}$ e $2^{\circ}$ graus, e dá outras providências. Diário Oficial da União, Brasília/DF, 12 ago. 1971.

BRASIL. Casa Civil. Lei № 9.394, de 20 de dezembro de 1996. Estabelece as diretrizes e bases da educação nacional. Diário Oficial da União, Brasília/DF, 23 dez. 1996.

\section{BRASIL. Ministério da Educação. Política Nacional de Educação Especial na Perspectiva da} Educação Inclusiva. Brasília/DF, jan. 2008. Disponível em:

http://portal.mec.gov.br/arquivos/pdf/politicaeducespecial.pdf. Acesso em: abr. 2020.

BRASIL. Secretaria-Geral. Lei No 13.146, de 6 de julho de 2015. Institui a Lei Brasileira de Inclusão da Pessoa com Deficiência (Estatuto da Pessoa com Deficiência). Diário Oficial da União, Brasília/DF, 7 jul. 2015.

CORREA, J.; MACLEAN, M. Era uma vez... um vilão chamado matemática: um estudo intercultural da dificuldade atribuída à matemática. Psicologia: Reflexão e Crítica, Porto Alegre, v. 12, n. 1, p. 173-194, 1999. DOI: http://dx.doi.org/10.1590/S0102-79721999000100012.

FIORENTINI, D.; MIORIM, M. A. Uma reflexão sobre o uso de materiais concretos e jogos no Ensino de Matemática. Boletim da SBEM, São Paulo, ano 4, n. 7, 1990.

FIORENTINI. D.; LORENZATO, S. Investigação em educação matemática: percursos teóricos e metodológicos. 3. ed. Campinas: Editores Associados, 2009.

OLIVEIRA, C. H; TRINDADE, V. M. T; ROBAINA, J. V. L. Uso do console Xbox $360^{\circ}$ com kinect no ensino de Matemática e Ciências. In: ENCONTRO REGIONAL DE ENSINO DE CIÊNCIAS, 2, 
2018, Porto Alegre. Anais... Porto Alegre: Universidade Federal do Rio Grande do Sul, 2018. Disponível em:

https://www.lume.ufrgs.br/bitstream/handle/10183/205986/001108988.pdf?sequence=1. Acesso em: abr. 2020.

PACHECO, M. B.; ANDREIS, G. da S. L. Causas das dificuldades de aprendizagem em Matemática: percepção de professores e estudantes do $3^{\circ}$ ano do Ensino Médio. Revista Principia, João Pessoa, v. 1, n. 38, p. 105-119, fev. 2018. DOI: http://dx.doi.org/10.18265/151703062015v1n38p105-119.

PIOVEZANI, M. I. E. Formação de professores e o atendimento ao aluno com deficiência no ensino regular na perspectiva da educação inclusiva. 2013. 105 f. Dissertação (Mestrado em Educação) - Programa de Mestrado em Educação, Universidade Estadual do Oeste do Paraná, Cascavel, 2013.

SANTOS, V. de M. A relação e as dificuldades dos alunos com a matemática: um objeto de investigação. Zetetike, Campinas, v. 17, n. esp., 9 dez. 2009.

DOI: https://doi.org/10.20396/zet.v17i0.8646794.

SANTOS, J. F. Atendimento educacional especializado para a educação infantil em redes municipais de ensino do estado do Rio Grande do Sul: Caxias do Sul, Porto Alegre, Santa Maria e Uruguaiana. 2017. 195 f. Dissertação (Mestrado em Educação) - Programa de PósGraduação em Educação, Universidade Federal do Rio Grande do Sul, Porto Alegre, 2017.

SILVEIRA, M. R. A. A dificuldade da Matemática no dizer do aluno: ressonâncias de sentido de um discurso. Revista Educação e Realidade, Porto Alegre, v. 36, n. 3, p. 761-779, set./dez. 2011. Disponível em: https://www.seer.ufrgs.br/educacaoerealidade/article/view/18480. Acesso em: abr. 2020.

SMOLE, K. S.; DINIZ, M. I.; PESSOA, N.; ISHIHARA, C. Cadernos do Mathema: Jogos de matemática de $1^{\circ}$ a $3^{\circ}$ ano. Porto Alegre: Artmed, 2008.

SOARES, M. A. L; CARVALHO, M. F. O professor e o aluno com deficiência. São Paulo: Cortez, 2012.

TATTO, F.; SCAPIN, I. J. Matemática: por que o nível elevado de rejeição? Revista de Ciências Humanas, Frederico Westphalen, v. 5. n. 5, 2004. Disponível em: http://revistas.fw.uri.br/index.php/revistadech/article/view/245. Acesso em: abr. 2020.

TIELLET, C. A.; FAlKeMBACH, G. A. M.; COLlETO, N. M.; SANTOS, L. R.; RIBEIRO, P. S. Atividades Digitais: seu uso para o desenvolvimento de habilidades cognitivas. RENOTE: Revista Novas Tecnologias na Educação, Porto Alegre, v. 5, n. 1, jul. 2007.

DOI: https://doi.org/10.22456/1679-1916.14152. 